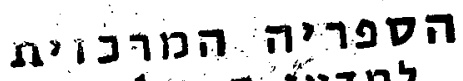

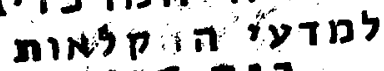

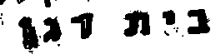

FINAL REPORT

PROJECT NO. US-1578-88

Nondestructive In-Line Determination of Moisture Content in Nuts and Dry Semi-dry Fruits by Dielectric Properties Sensing

S.O. Nelson, Z. Schmilovitch, A.W. Krazewski, A. Zaltzman 
DATE: January 28,1994

$$
42120
$$

BARD

P. O. BOX 6

Bet Dagan, ISRAEL

BARD project No. US-1578-88R

Title:

\section{NONDESTRUCTIVE IN-LINE DETERMINATION OF MOISTURE CONTENT IN NUTS AND DRY AND SEMI-DRY FRUITS BY DIELECTRIC PROPERTIES SENSING}

Investigators' Names (Principal listed first)

Stuart O. Nelson

Ze'ev Schmilovitch

Andrzej W. Kraszewski

Arthur Zaltzman (Proposal and initial plans)
Investigators' Institutions

U. S. Department of Agriculture, ARS Russell Research Center; Athens, GA, USA

Agricultural Engineering Institute A.R.O., Volcani Center, Bet Dagan, Israel

U. S. Department of Agriculture, ARS Russell Research Center, Athens, GA, USA

Agricultural Engineering Institute A.R.O., Volcani Center, Bet Dagan, Israel

Project's starting date: October 1, 1989

Type of Report: 1st Annual 2nd Annual Final $x$

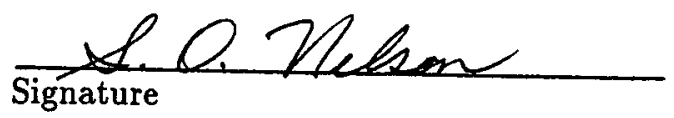

Principal Investigator

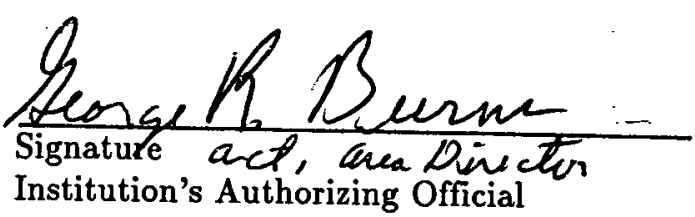




\section{TABLE OF CONTENTS}

ABSTRACT 3

OBJECTIVES OF THE ORIGINAL RESEARCH PROPOSAL $\quad 4$

FORMAT OF THIS REPORT

INTRODUCTION

DIELECTRIC-PROPERTY AND MOISTURE-SENSING RESEARCH INVESTIGATIONS 6

$\begin{array}{ll}\text { Dielectric Properties Measurements } & 6\end{array}$

$\begin{array}{ll}\text { Sensing Moisture Content in Pecans } & 7\end{array}$

Sensing Moisture Content in Dates $\quad 8$

ON-LINE PECAN CONVEYING AND MOISTURE TESTING SYSTEM 9

Single Channel Feeder $\quad 10$

$\begin{array}{ll}\text { Sensor } & 10\end{array}$

Electronic Dual-Frequency Impedance Measurement Unit $\quad 11$

Preliminary Calibration Experiments $\quad$ - 11

Integration of Impedance Measuring Instrument with Sensing and Conveying System 12

SUMMARY OF PROJECT ACCOMPLISHMENTS AND DISCUSSION

DESCRIPTION OF COOPERATION

EVALUATION OF THE RESEARCH ACHIEVEMENTS WITH RESPECT TO

THE AIMS OF THE ORIGINAL RESEARCH PROPOSAL $\quad 18$

LIST OF PUBLICATIONS RESULTING FROM THE PROJECT · $\quad 19$

ACKNOWLEDGMENTS $\quad 20$

REFERENCES 20

TABLES ? 21

FIGURES

$\begin{array}{ll}\text { APPENDIX A } & 29\end{array}$

$\begin{array}{ll}\text { APPENDIX B } & 37\end{array}$

$\begin{array}{ll}\text { APPENDIX C } & 43\end{array}$

APPENDIX D $\quad 53$

$\begin{array}{ll}\text { APPENDIX E } & 63\end{array}$

$\begin{array}{ll}\text { APPENDIX F } & 69\end{array}$

$\begin{array}{ll}\text { APPENDIX G } & 79\end{array}$

$\begin{array}{ll}\text { APPENDIX H } & 94\end{array}$

$\begin{array}{lr}\text { APPENDIX I } & 102\end{array}$ 


\begin{abstract}
Research was carried out under this project that established useful techniques for rapidly scnsing moisture content of individual pecans and dates by sensing their dielectric properties and that resulted in a prototype product feeding, singulation, and conveying system that presented the individual products to an on-line moisture sensor. Techniques explored for moisture sensing included dual-frequency RF impedance measurements on a parallel-plate capacitor system that held the product between and in contact with the plates and microwave resonant cavities into which the product was inserted for measurement. The resonant cavity technique required the measurement of the resonant frequency shift and the change in the cavity transmission characteristics that occurred when the individual pecan was introduced into the cavity. The impedance measurement technique required the measurement of the complex impedance of the parallel-plate sensor with a pecan or date between the plates at two frequencies, 1 and $5 \mathrm{MHz}$. Laboratory measurements demonstrated that pecan kernel moisture content could thus be sensed by impedance measurements on either whole pecans or pecan kernel halves after shelling with standard errors of 0.6 to $0.8 \%$ moisture content (m.c.) over a kernel moisture range from 3 to $11 \%$, wet basis. Similar measurements on dates resulted in standard errors of about $1 \%$ m.c. over the moisture range from 13 to $30 \%$ on either whole or pitted dates. The resonant cavity approach was less sensitive to moisture content and resulted in standard errors about twice those of the RF impedance method in sensing pecan kernel moisture for in-shell pecans. Further resonator studies on permittivity or dielectric properties measurement on whole pecan nuts revealed potential explanations for the insensitivity to kernel moisture in the nuts. The temperature dependence of the dielectric properties of pecan kernel material was determined by measurements over the 0.1 - to 110 $\mathrm{MHz}$ frequency range, 0 - to $40{ }^{\circ} \mathrm{C}$ temperature range and 3 to $9 \%$ kernel moisture range, which will be useful in development of practical moisture sensing systems. The microwave resonator approach was not suitable for measurements on dates.

An automated computer-controlled pecan feeder, singulation, and conveying system was designed, developed, and constructed in Israel, and a parallel-plate sensor, capable of holding each pecan in contact between the plates for the impedance measurements, was developed to meet the measurement requirements and installed in the stepwise conveyor developed for the system. A duplicate sensor assembly, electrically identical to the sensor assembly in the conveyor, was built and shipped to the U.S.A. for tests and calibration work in developing an inexpensive electronic RF impedance-measuring unit to be used with the on-line system in Israel. The electronic unit was then integrated with the automated conveying and sensing system and calibrated to provide kernel moisture contents in individual pecans with standard errors of $1.1 \%$ m.c.
\end{abstract}




\section{OBJECTIVES OF THE ORIGINAL RESEARCH PROPOSAL}

The objectives stated in the original proposal were as follows:

1. To establish the correlation between the dielectric properties of selected products and their moisture contents

2. To develop nondestructive in-line sensors for moisture content monitoring of selected products by use of their dielectric properties

3. To develop laboratory in-line mechanisms for sorting selected products according to moisture content

These objectives guided the conduct of research on this project, and all of the objectives were met with some degree of success as related in this report.

\section{FORMAT OF THIS REPORT}

Many of the findings of the research conducted on this project have already been reported in published papers or written papers prepared for presentation and publication. Therefore, those papers are appended to the report and will be referred to in the summarization presented in the body of the report. Those significant efforts not suitable for paper preparation or not yet prepared for publication will be included in the body of the report.

\section{INTRODUCTION}

The products selected for research on this project were pecans, nuts of the pecan tree, Carya illinoensis (Wangenh.) K. Koch, and dates, fruit of the date palm, Phoenix dactylifera L. Both crops are of economic significance in both the United States and Israel. Moisture content is important in the post-harvest handling of both dates and pecans.

For pecans, the maintenance of good quality requires that the nuts be dried to kernel moisture contents of about $4.5 \%$ as soon as possible after harvest (Appendix A). Then during the cracking and shelling processes, kernel moisture increases because of conditioning for cracking in order to minimize breakage of the kernel. Also, flotation in water is used for separation of kernel material and shell fragments, and this also raises the kernel moisture content. Several drying stages are used in most shelling plants during the separation processes, and the kernel moisture must be reduced to 3.5 to $4 \%$ for storage or packaging to maintain quality. The studies conducted on this project were aimed at rapidly sensing the kernel moisture content in individual in-shell pecans for possible sorting of pecan nuts into different moisture categories, with potential for energy conservation in the drying of nuts, and 
sensing of moisture content in individual pecan kernel halves after shelling so that moisture content could be monitored for automatic control of drying equipment and to provide tools for maintaining higher quality of the final product.

With dates, there are wide ranges in moisture content at harvest, because bunches of dates taken from the trees contain some dates that are too high in moisture for safe storage and some that are so dry they need to be rehydrated before they can be marketed (Nelson et al., 1992, Appendix A). Thus, the dates must be sorted immediately after harvest so that those that require drying can have the moisture levels reduced before they spoil. Moisture content is an important factor affecting the subjective determination of grade in hand sorting, and since all dates are presently hand sorted, it is a very labor-intensive industry. Automatic sorting of dates by moisture level could be useful in reducing these labor requirements. Therefore, the emphasis in this research was on sensing moisture content in whole and pitted individual dates, since any practical successful techniques could then be implemented at appropriate points in the date handling and sorting processes.

Since it is the dielectric properties of agricultural products that can be used to sense their moisture contents rapidly by radio-frequency and microwave fields (Nelson, 1973), the relationships between the dielectric properties of the materials and their moisture contents are important. Information on these relationships for chopped pecan kernels was available for the moisture range from $3 \%$ to $9 \%$ and the frequency range from $50 \mathrm{kHz}$ to $12 \mathrm{GHz}$ at $22{ }^{\circ} \mathrm{C}$ (Nelson, 1981). Relationships were also available for relating the dielectric properties of particulate dielectrics to those of the solid dielectrics (Nelson, 1992). However, the temperature dependence of these properties, which would be important in any practical applications of moisture sensing techniques using these properties, was unknown. Therefore, new measurements to determine the temperature dependence of the dielectric properties of pecan kernels were needed.

Two basic techniques were explored for sensing moisture content in pecans, 1) dual radiofrequency (RF) impedance measurements on individual nuts between and in contact with the electrodes of a small parallel-plate capacitor, and 2) the influence of the nut on the characteristics of a microwave resonant cavity. The dual-frequency RF impedance method was also explored for sensing moisture content in dates. The resonant cavity technique was not found appropriate for measurements on dates.

The work described in this report is organized into subunits in the following section, where each can be explained with respect to methods, equipment, procedures, findings, and results of each phase of the work. This follows a general chronological order involving the separate components of the project conducted in the United States and in Israel and finally the integration of the separate but 
coordinated activities. The studies leading to the identification of a suitable moisture sensor for the individual pecan nuts and dates were conducted as planned in the U.S.A., and the on-line sensor, singulation, and conveying mechanisms for presentation of the products to the sensor were developed as planned in Israel. Once the fundamental specifications for the experimental moisture-sensing electrode system were identified, the sensing electrode system was constructed in Israel for integration into the automatic conveying system. A duplicate electrode system was also constructed and shipped to the U.S.A., where it could be used with the laboratory impedance analyzer to establish its impedance characteristics and impedance values to be obtained with pecans and dates of different moisture levels. It was also later connected to the experimental dual-frequency impedance measuring electronic instrument designed and constructed for use in the on-line conveying system in Israel. The electrode system and impedance measuring instrument were calibrated with pecans of different moisture levels, and the instrument was then taken to Israel for use with the integral moisture sensing electrode and conveying system. Trials in Israel with pecans to demonstrate the usefulness of the technique concluded the work of the project.

\section{DIELECTRIC-PROPERTY AND MOISTURE-SENSING RESEARCH INVESTIGATIONS}

\section{Dielectric Properties Measurements}

To supplement the data already available on the dielectric properties of pecan kernel material (Nelson, 1981), measurements of the dielectric constant $\epsilon^{\prime}$ and dielectric loss factor $\epsilon^{\prime \prime}$ were taken on pecan kernel pieces of $3.2 \%$ to $8.9 \%$ moisture, wet basis, over the temperature range from 0 to $40{ }^{\circ} \mathrm{C}$ at frequencies from 0.1 to $110 \mathrm{MHz}$. Detailed descriptions and results of these measurements have been reported (Lawrence et al., 1992, Appendix B). Both $\epsilon^{\prime}$ and $\epsilon^{\prime \prime}$ decreased with increasing frequency at all moisture levels and temperatures. Nonlinear dependence of both $\epsilon^{\prime}$ and $\epsilon^{\prime \prime}$ on temperature was revealed, with both properties increasing as temperature increased in this range. Useful information on the values of these dielectric properties of the pecan kernel was established for subsequent use.

The microwave cavity perturbation technique was studied for measurement of the dielectric properties of whole pecan nuts, and details of this study have been reported (Kraszewski and Nelson, 1993, Appendix C). Differences in the equilibrium moisture content of the pecan kernel and the shell, with the shell having much higher moisture levels than the kernel, provide interesting questions with respect to sensing kernel moisture in a resonant cavity. Values for the effective $\epsilon^{\prime}$ and $\epsilon^{\prime \prime}$ of the whole nut were obtained between 1 and $2 \mathrm{GHz}$, and moisture insensitivity of a permittivity function was revealed that may explain the lack of sensitivity noted in resonant cavity measurements to detect kernel moisture content (Nelson et al., 1992, Appendix A). 


\section{Sensing Moisture Content in Pecans}

As mentioned, two different techniques were explored for sensing moisture content in pecans. The dual-frequency RF impedance measurement technique, which was originally developed for single kernel moisture measurement in corn, Zea mays L., (Kandala et al., 1989), was one of these approaches. The second was measuring the influence of the pecan on the resonant frequency shift and the change in the transmission characteristics of a microwave resonant cavity. The initial studies on both techniques with pecans were described in detail in a paper already published (Nelson et al., 1992, Appendix A).

The RF impedance measurements required an electrode assembly, for which 5-cm diameter parallel-plate electrodes were constructed for use with pecans. The impedance of this capacitor with individual pecans between and in contact with the electrodes was measured at two frequencies, 1 and 5 $\mathrm{MHz}$ (Nelson et al., 1992, Appendix A). Measurements were taken and the electrodes and pecan were represented as a series equivalent circuit with values for the complex impedance determined for each frequency. Moisture content of the pecan kernels and non-kernel material when shelled were determined by vacuum-oven drying standard techniques. Statistical techniques were then used to obtain calibration equations from which the kernel and whole-nut moisture contents could be calculated in terms of the complex impedance parameters. Such equations were developed from measurements on pecan nuts grown both in the southeastern United States and in. Israel. Calibration equations were obtained both for measurements on whole nuts and on individual kernel halves obtained when the nuts were shelled. Data were also obtained on the relative mass of the kernel and nonkernel (shell and corky partition material) components of the pecans and their equilibrium moisture contents.

Measurements of the frequency shift and change in transmission factor of a microwave resonant cavity were also used for estimating kernel moisture content (Kraszewski et al., 1990). The resonant frequency selected for the measurements in an L-band rectangular waveguide cavity was $1.7 \mathrm{GHz}$ (Nelson et al., 1992, Appendix A). These measurements were also calibrated against vacuum-oven moisture determinations as the reference, and an equation was developed for estimating the moisture content of the whole nut from the frequency shift and transmission factor change when the nut was inserted into the cavity. Kernel moisture content was obtained from the whole-nut moisture content (m.c.) with an empirical equation relating kernel m.c. and whole nut m.c. for U. S. pecans, and with another similar equation for Israeli pecans.

Kernel moisture prediction by both of these measurement techniques relies on the high correlation between kernel m.c. and whole nut m.c. determined in this work. Correlation coefficients 
(r) for these relationships were 0.98 and 0.95 for the four pecan cultivars grown in the U.S.A. and the two cultivars grown in Israel, respectively. Kernel moisture contents, which are of interest in commercial handling and processing, were predicted with standard errors of about $0.6 \%$ m.c. by the dual-frequency parallel-plate impedance measurements on either whole nuts or pecan kernel halves. The standard error of calibration for the microwave cavity technique was $1.5 \%$ m.c., which was much less sensitive to moisture than the parallel-plate RF impedance technique.

Pecans from the southeastern United States that were used for the initial studies and calibrations were grown in 1989. Pecans grown in the southeast in 1990 and 1991 were of poor quality and therefore not representative of normally well-filled nuts. For validation tests, therefore, three lots of different pecan cultivars from the 1989 crop that had been held in frozen storage and one lot of the better pecans from the $1991 \mathrm{crop}$, although inferior by normal standards, were used for validation tests in 1992. This work has also been described in detail (Nelson and Lawrence, 1993, Appendix D). The original calibration equations for the dual-frequency RF impedance measurements did not perform as well as expected for measurements on kernel halves. The standard error of performance for kernel moisture content from measurements on whole nuts was $0.82 \%$ m.c. and for measurements on kernel halves, it was $1.4 \%$ m.c. The poor performance on kernel halves prompted a re-examination of possible calibration equations based on the original data, and a new calibration equation was developed that provided $0.8 \%$ m.c. for measurements on kernel halves as well.

\section{Sensing Moisture Content in Dates}

The same techniques used for sensing moisture in pecans were explored for measurements on

dates. Preliminary measurements with dates in resonant cavities revealed that this technique was not appropriate for moisture sensing in the higher moisture dates. However, the dual-frequency RF impedance measurement technique proved useful. Initial measurements on dates of the Deglet Noor cultivar, grown in the Coachella Valley of California in 1988 and 1989, were used for the development of calibration equations, based on impedance measurements of individual dates between the same electrodes used for pecan measurements (Nelson and Lawrence, 1992a, Appendix E). These impedance measurements were taken in the parallel-equivalent-circuit mode at frequencies of 1 and $5 \mathrm{MHz}$ on dates ranging from 13 to $30 \%$, wet basis. The moisture content reference was again chosen as a vacuum-oven drying method. However; in this instance some drying experiments were performed to arrive at the 48-h drying period as the best choice for moisture determination on date flesh samples of the preparation chosen for this work (Nelson and Lawrence, 1992a, Appendix E). Date pit moisture contents were also determined and found to be of lower equilibrium moisture levels than the date flesh. 
From the calibration tests, equations for calculating moisture content of date flesh from the results of the dual-frequency impedance measurements were developed for both whole dates and pitted dates. Simple calibration equations with high coefficients of determination $\left(r^{2}=0.94\right)$, involving only the difference in capacitance at the two frequencies, 1 and $5 \mathrm{MHz}$, were obtained both for whole dates and pitted dates. Standard errors of calibration were about $1 \%$ m.c.

Dates of the same cultivar, Deglet Noor, from the same production region, grown in 1990 , were obtained for validation tests. Standard errors of prediction were comparable to the standard error of calibration, about $1 \%$ m.c. Finally the measurement data on the 1988, 1989 and 1990 dates were all combined to provide a new calibration with a standard error of $0.9 \%$ m.c. for both whole and pitted dates (Nelson and Lawrence, 1992b, Appendix F).

\section{ON-LINE PECAN CONVEYING AND MOISTURE TESTING SYSTEM}

One of the main objectives of this project was the development of a prototype of a nondestructive, on-line pecan moisture detecting system. Preliminary considerations indicated that the basic requirements include a feed system with an on-line application of an RF moisture sensor. The requirements of the feed system could be stated as follows:

1. Capability for pecan singulation

2. Facility for contact of the product with two electrodes of the RF moisture sensor.

To meet these requirements, the Israeli team worked on several topics as follows:

a. Single channel feeder

b. Continuous, stepwise, electrode sensor

c. Combining the two systems, $a$ and $b$

d. Calibration of the entire system

Following experience gained in sensing moisture content of individual pecans during the first year of the research, the requirements for the feed system were defined. The approach of sorting according to dielectric properties sensed between parallel-plate electrodes required a system with stepwise motion rather than a continuous system providing free fall through a tube, which was one sensing possibility initially envisioned if a microwave resonant cavity might be used as the moisture sensor. A prototype device was designed, developed, and built. The final characteristics of the prototype were selected as follows:

1. Product-electrode contact during the measuring period

2. Electrodes of circular shape about $5 \mathrm{~cm}$ in diameter 
3. Product and electrodes in static position for at least $100 \mathrm{~ms}$ during measurement period

4. Handling rate for one channel of about four products per second

\section{Single Channel Feeder}

The feeder was based on a special assembly of 52 pecan-holding blocks attached to a vibrated chain conveyor (Fig. 1). Each block was drilled with four holes to provide singulation of pecans for four channels, with each block collecting four single nuts. At the stage shown, however, only one channel was used. Tests conducted with pecan nuts yielded a filling rate of 94 to $96 \%$ when operated at the capacity of four blocks per second.

To meet the requirements, an additional system was developed, consisting of cells machined from Delrin blocks and attached to a chain conveyor running below the four-channel drilled-block conveyor (Fig. 1). The cells conveyor and the drilled-blocks conveyor are synchronized in such a manner that the nut transfers from the drilled block to the cell during conveying. The object of the Delrin cell conveyor is to carry the nut to the parallel-plate sensor and to allow the electrodes to contact the nut from both sides. The cells were constructed of Delrin to minimize interference with the electric field between the electrodes for sensing moisture content of the pecans. The chain operated stepwise to meet the measurement requirements under computer control through a programmable logic controller (PLC) which drives a stepping motor to operate the conveyor.

\section{Sensor}

The moisture sensor (Figs. 2 and 3) is based on two parallel, round stainless steel plates, 50 $\mathrm{mm}$ in diameter and $1 \mathrm{~mm}$ in thickness. The electrodes were attached with an adhesive to Delrin base plates which were each mounted on round steel rods. The purpose of the Delrin plates was to provide RF electrical insulation from the rods and the rest of the mechanical system. Each rod, which is aligned by a Delrin block nub is pulled by a pneumatic cylinder against the force of a spring. The release of the cylinders creates a movement of the electrodes toward the nut in the cell for contact with the nut. The mechanical connection between the cylinder and the rod is made by a flexible-link (chain) which permits only the spring force to be exerted against the nut by the plate electrode. The springs were adjusted so that the pressing force on the nut was in the range from 0.2 to $0.5 \mathrm{~N}$. An electrode assembly, mounted in a section of the conveyor supporting structure, with a section of the conveyor chain including three attached Delrin pecan-cell blocks, was shipped from the Volcani Center to the Russell Research Center to serve as a duplicate of the sensing electrode system mounted in the conveying system. This duplicate electrode assembly (Fig. 4) was electrically identical to the one in 
the automatic conveyor system in Israel (Fig. 5), and was furnished for testing and use in developing the impedance measuring unit and calibration by the American team. It was mechanically identical also, except that knobs were supplied on the ends of the rods that supported the electrodes for manual operation instead of being pneumatically controlled as in the automatic conveying system. Coaxial type BNC connectors were mounted on the Delrin blocks, which held the electrode supporting rods in alignment, for connection of the coaxial cables for the electronic impedance measurement unit. The electrical connection from the central conductor to the movable stainless steel electrodes was made with a short loop of flexible wire to a threaded connection post welded to each electrode.

\section{Electronic Dual-Frequency Impedance Measurement Unit}

An electronic dual-frequency impedance measuring unit was designed and constructed for use in sensing the moisture content of pecans to be tested in the automatic conveying and moisture sensing electrode system. The circuits employed in this instrument design were very similar to those described previously (Kandala et al., 1993). However, the two frequencies chosen for this new instrument were 1 and $5 \mathrm{MHz}$ instead of 1 and $4.5 \mathrm{MHz}$, and the physical layout was much improved from the standpoint of mechanical stability and convenience for servicing and adjustment. This electronic unit is pictured in Fig. 5, along with the duplicate sensing electrode assembly shipped from Israel to the U.S.A for testing and calibration work. The PC (printed-circuit) boards and components of the 1-MHz and 5$\mathrm{MHz}$ impedance measuring circuits are shown in Fig. 7, where the rear panel of the instrument cabinet has been removed for access.

A detailed description of the instrument is given in Appendix G, which was prepared at the time the instrument was shipped from the Russell Research Center, where it was constructed and initially calibrated, to the Volcani Center. This write-up was prepared as a general description and to serve as instructions for using the instrument, troubleshooting the circuits if necessary, and recalibration if that should be required. Included along with the written information, were drawings of the component layout with test-point locations, location of trimming potentiometers for adjustment, and circuit diagrams.

\section{Preliminary Calibration Experiments}

During the visit of the Israeli Investigator to the Russell Research Center in June of 1992, pecans with a range of moisture contents were tested in the duplicate sensing-electrode assembly (constructed in Israel and shipped to the Russell Research Center) connected to the HP 4192A LF 
Impedance Analyzer ${ }^{1}$. Results of this test showed good agreement with moisture determinations made by the dual-frequency impedance measurements on the same pecans in the laboratory parallel-plate electrode assembly (Fig. 8). These results for distinguishing different pecan-kernel moisture levels in intact pecan nuts were promising enough to proceed with calibration of the electrode assembly and the newly constructed electronic impedance sensing instrument as soon as it was completed. A preliminary calibration on pecans was completed with this combination just prior to the Principal Investigator's visit to the Volcani Center in December, 1992. He carried the new electronic unit and connecting cables with him to the Agricultural Engineering Institute laboratories for the initial trials of the integrated system.

Integration of Impedance Measuring Instrument with Sensing and Conveying System

Prior to the Principal Investigator's visit to the Volcani Center, information on computer interface requirements for the dual-frequency impedance-measuring instrument was exchanged and an A-D card with suitable versatility and specifications was installed in the personal computer which controlled the programmable logic controller for the automatic conveying system and would acquire the data from the impedance measuring instrument from which the pecan moisture content could be computed according to the calibration equation. Several problems were encountered in integrating the moisture-sensing conveyor system. Spurious signals were finally eliminated and voltages were acquired by the computer, but their magnitudes were not as expected. Examination of waveforms at test points in the electronic impedance measuring unit revealed that waveforms had changed and that spurious RF noise was present. Changes were made in the grounding of circuits in attempts to remedy the problem, and several attempts were made to readjust the circuit after IC (integrated circuits) replacements, etc., so that a recalibration could be done. However, these attempts to restore proper operation of the electronic unit were not successful after several days of. effort, and the decision was made to bring the instrument back to the Russell Research Center for correction and further testing.

Several minor circuit changes, including a revision of the grounding system, to improve the stability of the circuits were completed, and the system was recalibrated and tested for several weeks. When it appeared that suitable stability had been maintained, the electronic unit was repackaged and shipped back to Israel for reconnection into the automatic sensing and conveying system. The new calibration equation for the computation of moisture content, $M$, in \%,"w.b., from impedance

${ }^{1}$ Mention of company or trade names is for purpose of description only and does not imply endorsement by the U. S. Department of Agriculture or the Israeli Agricultural Research Organization, Ministry of Agriculture. 
measurement parameters from the dual-frequency impedance-sensing instrument was as follows:

$$
M=185.3070-97.4458 V_{1}+103.4114 V_{4}+10.2061\left(V_{2} / V_{3}\right)-1.9394\left(V_{5} / V_{6}\right)
$$

where $V_{1}$ and $V_{4}$ are output dc voltages proportional to the impedance phase angles measured in the 1and 5-MHz circuits, respectively, $V_{2}$ and $V_{5}$ are constant reference dc voltages from the 1- and 5-MHz circuits, respectively, and $V_{3}$ and $V_{6}$ are dc voltages proportional to impedance magnitude measured by the $1-$ and $5-\mathrm{MHz}$ circuits respectively. The standard error of calibration was $1.14 \%$ m.c. This calibration is illustrated in Fig. 9 for the kernel moisture content range from 2 to $11 \%$.

Upon receipt of the electronic impedance measurement unit again in Israel, it was connected into the moisture sensing and conveying system. The output voltages $V_{1}$ to $V_{6}$ for empty-cell conditions were not found to be as expected for all outputs. Examination of waveforms and attempts to readjust the circuits, with communication by Fax and BITNET for guidance, were not successful in restoring the electronic unit to normal operation. Therefore, a decision was made to send Dr. C. V. K. Kandala to Israel to troubleshoot the problems. After replacing some defective components and working with Israeli personnel for a couple of days, he was able to assess the problems and make the necessary modifications. When connected into the on-line conveying system, the $5-\mathrm{MHz}$ signal was somehow being attenuated to a low level. An amplifier stage and buffer were added to provide the necessary higher output signal amplitude from the $5-\mathrm{MHz}$ circuit to the sensing electrodes, and suitable stability of the operating circuits was obtained. Upon recalibration, the expected performance of the electronic impedance measuring circuit installed in the sensing and conveying system was achieved. Recommendations concerning modifications of the impedance-sensing circuits for potential use on high moisture content fresh dates were also discussed.

The developed on-line system (Fig. 10) was tested in several experiments to evaluate its ability to measure moisture content of single pecans. The feeder and the sensor were tested for continuous mechanical operation. With the impedance-measuring electronic unit connected to the on-line sensor, simulations of a one-channel sorting system -were conducted. To evaluate the repeatability of the moisture measurements, a uniform cylindrical wooden model was measured. The cylindrical wooden model was 1 inch in diameter with a length of 2 inches. The model was soaked in water for one hour, acquiring a moisture content of $10 \%$. These measurements included repetition for the same Delrin cell and comparison between the different cells. Output readings representing the impedance characteristics were stored in the PC. Results of these test (Fig. 11 and Table 1) revealed standard deviations of $0.49 \%$ m.c. for measurements on the same cell and $0.83 \%$ m.c. for measurements on different cells. 
Three experiments were conducted with pecans for calibration of the system, since a new calibration was needed for the moisture sensing system when installed with the full conveyor. In each test about 40 pecans, cv. 'Delmas', were placed into the special conveyor cells, and when each was in contact with the sensor electrodes, the impedance characteristics were scanned and stored in the computer. The kernel moisture content of the individual pecans was determined by destructive methods and constants for the calibration equation (Equation 1) were determined by stepwise multiple regression techniques (SAS PROC REG procedures - SAS/STAT Guide for Personal Computers, Version 6 ed., SAS Institute, Inc., Cary, NC, USA). In the first of the three experiments, a quick method of moisture determination was implemented using a dc moisture detector (HE-50, Bauman Co.). The standard error obtained was $1.04 \%$ m.c. In the other two experiments, vacuum oven drying for $6 \mathrm{~h}$ was the reference method. For the two oven-reference experiments, standard errors of the pecan kernel moisture contents predicted by the RF impedance measurements were 1.15 and $1.12 \%$ m.c. Visual results of the two calibration tests, based on the vacuum oven reference, are illustrated in Figs. 12 and 13.

\section{SUMMARY OF PROJECT ACCOMPLISHMENTS AND DISCUSSION}

The following major accomplishments of the research project can be cited:

1. The temperature dependence of the dielectric properties of pecan kernel material was determined over the temperature range from 0 to $40^{\circ} \mathrm{C}$, the moisture content range from 3 to $9 \%$, w.b., and the frequency range from 0.1 to $110 \mathrm{MHz}$.

2. The dual-frequency parallel-plate impedance measurement technique was established as useful, with laboratory measurements at 1 and $5 \mathrm{MHz}$, for sensing the moisture content of individual pecans, and a standard error of performance of $0.8 \%$ m.c. was achieved both for measurements of kernel m.c. over a range from 3 to $11 \%$ on in-shell pecans and on pecan kernel halves after being shelled.

3. The microwave resonant cavity perturbation technique was found less sensitive to moisture variation in whole pecan nuts, with a standard error more than twice that of the parallel-plate impedance measurements.

4. New information on the microwave dielectric properties of intact pecan nuts was developed at 23 and $40^{\circ} \mathrm{C}$ at frequencies between 1 and $2 \mathrm{GHz}$, and an explanation was obtained for the lack of sensitivity of microwave perturbation methods in sensing moisture content of such objects.

5. An automated feeder and single pecan or date conveying system was developed that singulated the product with about $95 \%$ filling efficiency and presented the product in stepwise fashion, with capacity for up to four pecans per second, to the sensor for impedance measurements for predicting moisture content. 
6. A parallel-plate impedance sensor was developed for use in an automated on-line conveying system that can handle individual pecans at a capacity of up to four per second while holding the pecan stationary for a period and in contact with the electrodes for the RF electrical impedance measurements.

7. The dual-frequency parallel-plate impedance measurement technique was established as useful, with laboratory measurements at 1 and $5 \mathrm{MHz}$, for sensing moisture content of individual dates over the m.c. range from 13 to $30 \%$, w.b., with standard errors of about $1 \%$ m.c. for both whole and pitted dates.

8. A dual-frequency RF impedance sensing circuit was designed and constructed for use with the parallel-plate sensor for the automated conveying system that could be calibrated to provide detection of pecan kernel moisture content in whole pecan nuts over the kernel moisture range from 2 to $11 \%$ with standard errors of performance slightly over $1 \%$ m.c.

9. A totally integrated pecan singulation, moisture sensing, and conveying system was calibrated to provide pecan kernel moisture contents with standard errors of calibration of $1.1 \%$ m.c.

Since the RF impedance sensing technique is sensitive to any moisture between the electrodes, it responds to moisture in the pecan shell and corky partition material as well as that in the kernel. Because the shell and other nonkernel material in the nut has a higher equilibrium moisture content than the kernel material, nonequilibrium moisture distribution in the nut between the kernel and the shell could contribute to inaccuracies in the moisture determination by this method. Also, as a result of the variation in the kernel-to-shell mass ratio among different kinds of pecans or pecans of the same cultivar grown in different seasons, some error in moisture determination is likely to result, and the magnitude of this error would need to be determined for any practical use if the highest degree of accuracy in m.c. determination is desired.

Obviously, calibrations could be determined for different kinds of nuts by comparing impedance related data from the instrument to the moisture determinations on individual pecans by vacuum-oven drying or other standard reference methods. With the different pecan cultivars used in this research, there was a high correlation between the kernel moisture content and the moisture content of the whole nut (Appendix A). However differences in this relationship were noted, between the thin shelled nuts grown in the southeastern United States and the heavier shelled cultivars that we used from Israel, which resulted from the differences in kernel-to-shell mass ratios.

With additional effort, improvements could be achieved in the design of an electronic unit for impedance sensing. A more robust design for commercial use, instituting associated design and construction improvements would probably result in greater circuit stability and simpler and fewer 
calibration adjustments. Improvements in design and construction of all components of the integrated system could most likely be achieved with the usual effort going into commercial manufacture.

The maximum rate for single pecan moisture sensing measurements in such a system was not ascertained in this work. If higher capacities are required when that practical limit is reached, larger capacities could easily be achieved by multiple channels, as was anticipated in the four-abreast design of the pecan feeder mechanism (Fig. 1). Components of the RF impedance sensing electronic circuits are relatively low in cost, amounting to perhaps as little as $\$ 100$ to $\$ 200$ if obtained in quantity. Thus, if further development indicates practical application potential, the economic obstacles to development and manufacture of suitable equipment for such systems should be minimal.

\section{DESCRIPTION OF COOPERATION}

Cooperation in the first year involved the furnishing of pecans grown in Israel for the electrical sensor research conducted in the United States and several telephone conferences regarding progress of the work and the nature of electrical sensors to be planned for in the mechanical feed and conveying system research. Personal discussions between the principal investigator and Dr. Zaltzman were also held during the American Society of Agricultural Engineers National Meetings.

Cooperation during the second year involved the exchange of information relating to the sensor selected for further development and the consequent requirements for the mechanical conveying mechanisms necessary for on-line moisture sensing. Several letters and Fax exchanges were used in conveying information about the details of the sensor design requirements both ways between Israel and the United States. Telephone discussions between U. S. and Israeli investigators were also helpful in the coordination of efforts.

Cooperation during the third year was very frequent with coordination of the mechanical handling equipment under development and fine tuning the specifications of both that system and the moisture sensing and impedance measuring equipment. Mr. Schmilovitch visited the U. S. Investigators at the Russell Research Center in Athens in June of 1992, after the duplicate sensor mechanism constructed in Israel had been sent to the Principal Cooperator, and preliminary calibrations were made with pecans in this sensor attached to the impedance analyzer that had been used for all the earlier laboratory impedance measurements.

During this visit Mr. Schmilovitch presented a seminar at the Department of Biological and Agricultural Engineering at The University of Georgia. Also during this time the Investigators from both Countries visited a pecan shelling and processing plant near Harlem, Georgia, to obtain further 
information on problems in practice that our research might help to solve. Also during the visit in Athens, GA, plans were made for cooperative tests in Israel. During this visit and in the fall of 1992, information was exchanged on requirements for experimental equipment needed for the combination of the impedance sensing electronic unit being constructed at the Russell Research Center and the automated conveying mechanism and sensor built into the conveying system in Israel. Details of the requirements for A-D converters used with the computers were worked out, and suitable equipment was lined up for this purpose.

In December, 1992, the Principal Investigator traveled to Israel for a ten-day visit, taking along the newly finished and calibrated electronic dual-frequency impedance measuring unit to be integrated with the on-line sensor and conveying system. After several days working on problems associated with this project and attempting to obtain suitable operation of the electronic impedance measurement unit, the decision was made to take the unit along back to the U.S.A. for repair, adjustment, and further design improvements. Seminars were presented at the Volcani Center and at the Technion in Haifa during the Principal Investigator's visit to Israel.

In February 1993, after obtaining a second extension of the Project without additional funding, corrections of the electronic unit and recalibration were completed, and the unit, together with detailed circuit diagrams, instructions, troubleshooting guidelines, and spare special components and replacement IC's, was shipped by air express to the Volcani Center. Upon connection into the sensor and conveying system, the impedance measuring unit failed to operate satisfactorily. After a few weeks of troubleshooting with responses and guidance by Fax and BITNET communication, it became clear that Dr. Kandala's experience with the electronic unit, which he designed and built, was needed on-site in Israel. Within one week he was on his way, having obtained approval from ARS, USDA, and The University of Georgia, a passport renewal, and visitor's visa.

After a few days of intensive work on Dr. Kandala's part and that of the Israeli Cooperators, the unit was functioning satisfactorily, and an initial calibration with pecans of different moisture levels was accomplished. Data for the calibration were transmitted by BITNET to the Principal Cooperator and the regression analyses were performed to obtain the new calibration constants. These procedures were repeated for additional calibrations after Dr. Kandala returned, and communication by Fax and BITNET continued during the preparation of the Final Report. 


\section{EVALUATION OF THE RESEARCH ACHIEVEMENTS WITH RESPECT TO THE AIMS OF THE ORIGINAL RESEARCH PROPOSAL}

The aims of the original research proposal were quite well met in the achievements of the research conducted over the period of the extended project. Correlations between the dielectric properties of both pecans and dates (Objective No. 1) were utilized in the sensing of moisture content, particularly through the influence of the moisture in the individual products on the impedance of the parallel-plate capacitive sensor. Following laboratory measurements that established the feasibility of moisture sensing by the dual-frequency impedance measurement method, a sensor was designed and constructed for use in the automated feeder; singulation and stepwise conveyor system satisfying Objective No. 2.

Objective No. 3 was met reasonably well in that in-line mechanisms were developed that could easily be used for sorting products according to moisture content. The final calibrations on pecans with the electronic dual-frequency impedance measuring unit connected to the on-line sensor as an integral part of the stepwise conveyor show that kernel moisture content can be measured with standard errors of $1.1 \%$ m.c., which would be accurate enough for practical use in making separations by moisture levels. The extension of the conveyor to provide the physical separation of the pecans into the desired number of categories could be easily accomplished with available technology.

While time did not permit testing the new in-line moisture monitoring system with dates, there is no reason to doubt that this can be done successfully, based on the success achieved in the laboratory measurements. With semidry dates of the U. S. date industry, development work would need to be done on handling equipment to avoid the accumulation of residue from the dates, and the system may not work very well on such dates of high moisture levels when they become too sticky. However, there is interest in moisture sorting of fresh dates in Israel, and residue problems with this product should be less troublesome. A more detailed assessment of the benefits that might be achieved by the application of such moisture sorting equipment in the date industry is needed to evaluate the potential for further development of equipment to effectively sort dates. Since date sorting and grading is such a labor-intensive operation, a separation of the raw products into a few different moisture categories with automatic equipment could substantially reduce the skilled labor requirements for these operations. An initial separation at harvest of those dates that need to be dried immediately to avoid spoilage and those that can be stored for later sorting and grading would reduce the skilled labor requirements at harvest and permit a leveling of the labor requirements over a longer period for processing and packaging. 
With respect to pecan processing, the ability to sort in-shell pecans according to moisture levels would not appear to be directly applicable to current processing lines, because they routinely wash all the incoming pecans in the cleaning plants and dry all of them in the same way. There may be opportunities for energy conservation and reduction of drying costs if the processes were modified to institute whole pecan sorting by moisture levels at appropriate points in the schedules. The value of such a practice would also need to be assessed in the potential improvement in quality of the end product when overdrying and inadequate moisture removal might both be avoided by a separation into different moisture categories.

There would appear to be potential beneficial application of pecan kernel moisture sensing and separation by moisture categories after shelling to avoid overdrying, which is not only costly from an energy standpoint, but is also a factor in quality degradation. Reliable automatic moisture monitors on the input and output of driers used in the pecan shelling and cleaning operations would also offer opportunities for significant energy and cost savings. Another potentially rewarding application of a kernel moisture sensor would be for the detection and removal of the occasional high-moisture kernels just before packaging. Inclusion of such high-moisture kernel halves in the packaged product are most troublesome in producing spoilage before the products are consumed.

The principles developed in this research for moisture monitoring in individual products might also have potential for application to other agricultural products not considered in this project. Products that are subject to wide moisture variation and in which moisture content is important for particular end uses should be candidates for consideration. The eventual evaluation of the research conducted on this project in terms of benefits to agriculture must await such future considerations and applications.

\section{LIST OF PUBLICATIONS RESULTING FROM THE PROJECT}

1. Lawrence, K. C., S. O. Nelson, and A. W. Kraszewski. 1992. Temperature dependence of the dielectric properties of pecans. Trans. ASAE 35(1):251-255.

2. Nelson, S. O., K. C. Lawrence, and A. W. Kraszewski. 1992. Sensing moisture content of pecans by RF impedance and microwave resonator measurements. Trans. ASAE 35(2):617-623.

3. Nelson, S. O. , and K. C. Lawrence. 1992. Sensing moisture content in dates by RF impedance measurements. Trans. ASAE 35(2):591-596.

4. Nelson, S. O., and K. C. Lawrence. 1992. RF impedance sensing of moisture content in individual dates. ASAE Paper No. 926507, American Society of Agricultural Engineers, St. Joseph, MI, USA.

5. Nelson, S. O., and K. C. Lawrence. 1993. RF impedance sensing of moisture content in single dates. IV International Symposium on Fruit, Nut, and Vegetable Production Engineering, March 22-26, Valencia-Zaragoza, Spain. pp. 119-120 (Abstract). 
6. Nelson, S. O., K. C. Lawrence, and A. W. Kraszewski. 1993. RF impedance sensing of moisture content in single pecan nuts. IV International Symposium on Fruit, Nut, and Vegetable Production Engineering, March 22-26, Valencia-Zaragoza, Spain. pp. 121-122 (Abstract).

7. Kraszewski, A. W., and S. O. Nelson. 1993. Microwave permittivity of pecan nuts. J. Microwave Power Electromag. Energy 28(3):165-173.

8. Nelson, S. O., and K. C. Lawrence. 1993. Nondestructive moisture determination in individual pecans by RF impedance measurements. ASAE Paper No. 936546, American Society of Agricultural Engineers, St. Joseph, MI, USA.

9. Nelson, S. O., and K. C. Lawrence. 1993. RF impedance sensing of moisture content in single dates. Proceedings of the IV International Symposium on Fruit, Nut, and Vegetable Production Engineering, March 22-26, Valencia-Zaragoza, Spain. (Full-length paper submitted - Appendix H)

10. Nelson, S. O., K. C. Lawrence, and A. W. Kraszewski. 1993. RF impedance and microwave sensing of moisture content in single pecan nuts. Proceedings of the IV International Symposium on Fruit, Nut, and Vegetable Production Engineering, March 22-26, Valencia-Zaragoza, Spain. (Full-length paper submitted - Appendix I)

\section{ACKNOWLEDGMENTS}

The authors acknowledge the support of the BARD program, without which this research could not have been conducted. The capable assistance of A. Hoffman and H. Egozi with the work conducted at Bet Dagan, Israel, is gratefully acknowledged. The valuable assistance of Kurt Lawrence with much of the laboratory and analysis work at Athens, Georgia, is also gratefully acknowledged. The valuable contribution of Dr. Chari V. K. Kandala, in designing and constructing the special dual-frequency impedance measuring instrument, and his travel to Israel for trouble-shooting and design modification, along with the cooperation of the Research Services Office and the Agricultural and Biological Engineering Department of The University of Georgia, is also much appreciated. Gratitude is expressed to John Davies, Dole Dried Fruit and Nut Co., Thermal, California, for background information on date production and processing and for furnishing the dates used in the research. The assistance of the Nut Tree Pecan Company, Albany, Georgia, U.S.A., and the Tracy Luckey Pecan Company, Harlem, Georgia, U.S.A., in furnishing the pecans needed for this study is also gratefully acknowledged.

\section{REFERENCES}

Kandala, C. V. K., S. O. Nelson, and K. C. Lawrence. 1989. Non-destructive electrical measurement of moisture content in single kernels of corn. J. Agric. Eng. Res. 44:125-132.

Kandala, C. V. K., S. O. Nelson, R. G. Leffler, K. C. Lawrence, and R. C. Davis. 1993. Instrument for single-kernel nondestructive moisture measurement. Trans. ASAE 36(3):849-854. 
Kraszewski, A. W., and S. O. Nelson. 1993. Microwave permittivity of pecan nuts. J. Microwave Power Electromag. Energy 28(3):165-173.

Kraszewski, A. W., S. O. Nelson, and T.-S. You. 1990. Use of a microwave cavity for sensing dielectric properties of arbitrarily shaped biological objects. IEEE Trans. Microwave Theory \& Techn. $38(7): 858-863$.

Lawrence, K. C., S. O. Nelson, and A. W. Kraszewski. 1992. Temperature dependence of the dielectric properties of pecans. Trans. ASAE 35(1):251-255.

Nelson, S. O. 1973. Electrical properties of agricultural products - a critical review. Trans. ASAE $16(2): 384-400$.

Nelson, S. O. 1981. Frequency and moisture dependence of the dielectric properties of chopped pecans. Trans. ASAE 24(6):1573-1576.

Nelson, S. O. 1992. Estimation of permittivities of solids from measurements on pulverized or granular materials. Ch. 6 in Dielectric Properties of Heterogeneous Materials, A. Priou, ed., Vol. 6, Progress in Electromagnetics Research, J. A. Kong, chief ed., New York: Elsevier Science Publishing Co.

Nelson, S. O. , and K. C. Lawrence. 1992a. Sensing moisture content in dates by RF impedance measurements. Trans. ASAE 35(2):591-596.

Nelson, S. O., and K. C. Lawrence. 1992b. RF impedance sensing of moisture content in individual dates. ASAE Paper No. 926507, American Society of Agricultural Engineers, St. Joseph, MI, USA.

Nelson, S. O., and K. C. Lawrence. 1993. Nondestructive moisture determination in individual pecans by RF impedance measurements. ASAE Paper No. 936546, American Society of Agricultural Engineers, St. Joseph, MI, USA.

Nelson, S. O., K. C. Lawrence, and A. W. Kraszewski. 1992. Sensing moisture content of pecans by RF impedance and microwave resonator measurements. Trans. ASAE 35(2):617-623.

Table 1. Means and standard deviations of impedance unit output voltages and moisture contents ${ }^{1}$ for repeated measurements on wooden cylinder in Delrin cells between sensor electrodes

\begin{tabular}{lrrrrrrr}
\hline & $V_{1}$ & \multicolumn{1}{c}{$V_{2}$} & \multicolumn{1}{c}{$V_{3}$} & \multicolumn{1}{c}{$V_{4}$} & \multicolumn{1}{c}{$V_{5}$} & $V_{6}$ & Moisture content \\
\hline \multirow{2}{*}{ One cell } & & & & & & & \\
& -0.6569 & -0.7753 & -1.6105 & -1.0897 & -2.4094 & -0.1805 & $8.6650 \%$ \\
& 0.0289 & 0.0016 & 0.0030 & 0.0128 & 0.0016 & 0.0016 & $0.4933 \%$ \\
Different & -0.7110 & -0.7718 & -1.6130 & -1.0798 & -2.4089 & -0.1767 & $7.5875 \%$ \\
cells & 0.0378 & 0.00204 & 0.0069 & 0.0200 & 0.0016 & 0.0023 & $0.8258 \%$ \\
\hline
\end{tabular}

${ }^{1}$ Calculation from impedance-related data based on pecan calibration 


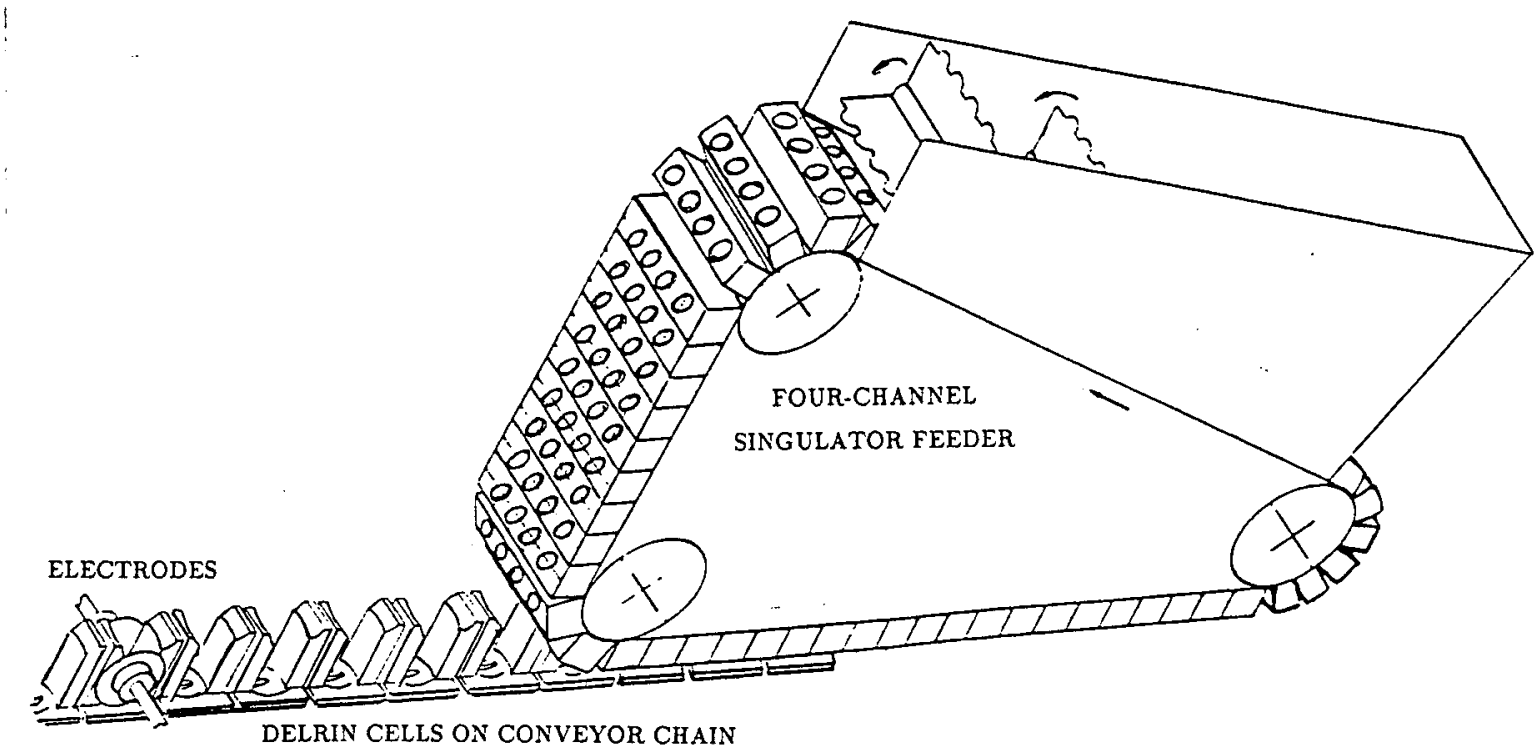

Figure 1. Schematic view of four-channel pecan feeder and singulation mechanism showing the synchronized, single-channel receiving pecan-cell chain conveyor that carries the individual pecans in stepwise movement to the electrodes for moisture sensing.

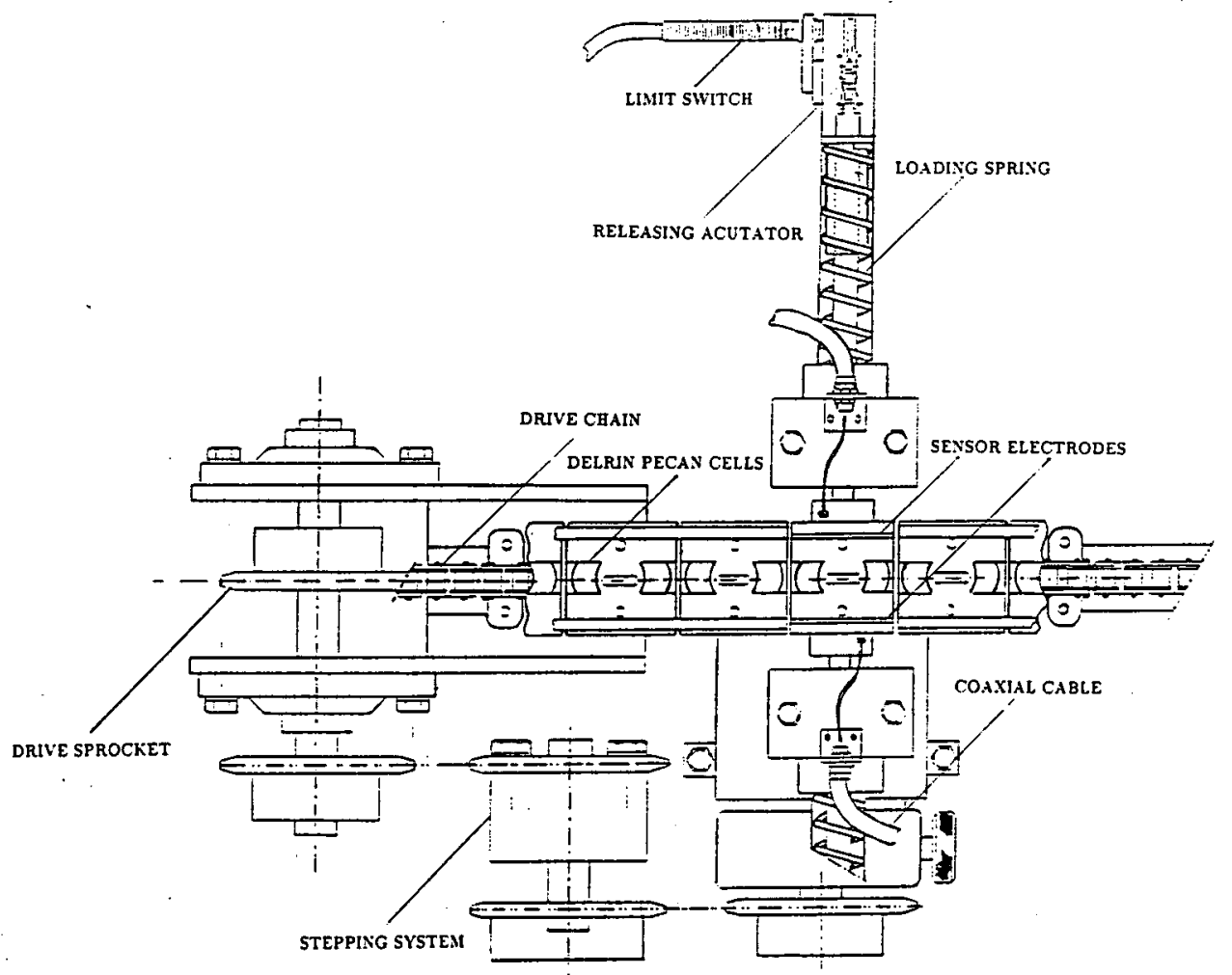

Figure 2. Top view of parallel-plate electrode sensor assembly, showing Delrin pecan-cell conveyor and other key components of the conveying system. 


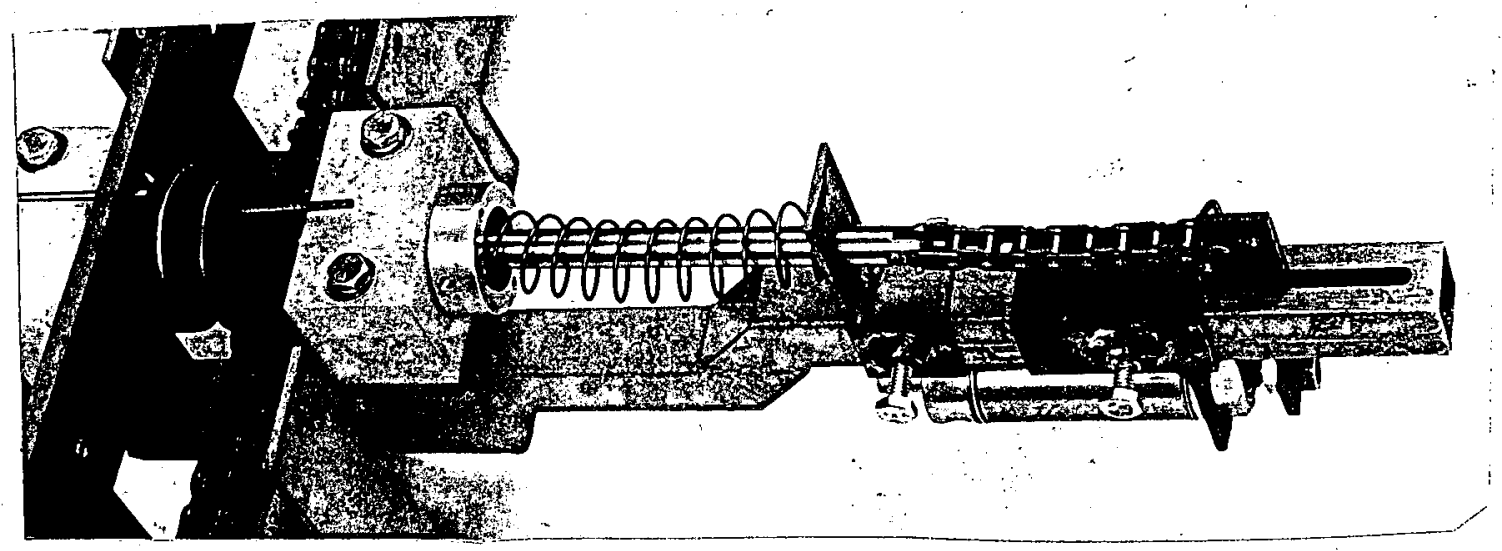

Figure 3. Parallel-plate electrode sensor assembly mounted above the chain conveyor to which Delrin cells were attached.

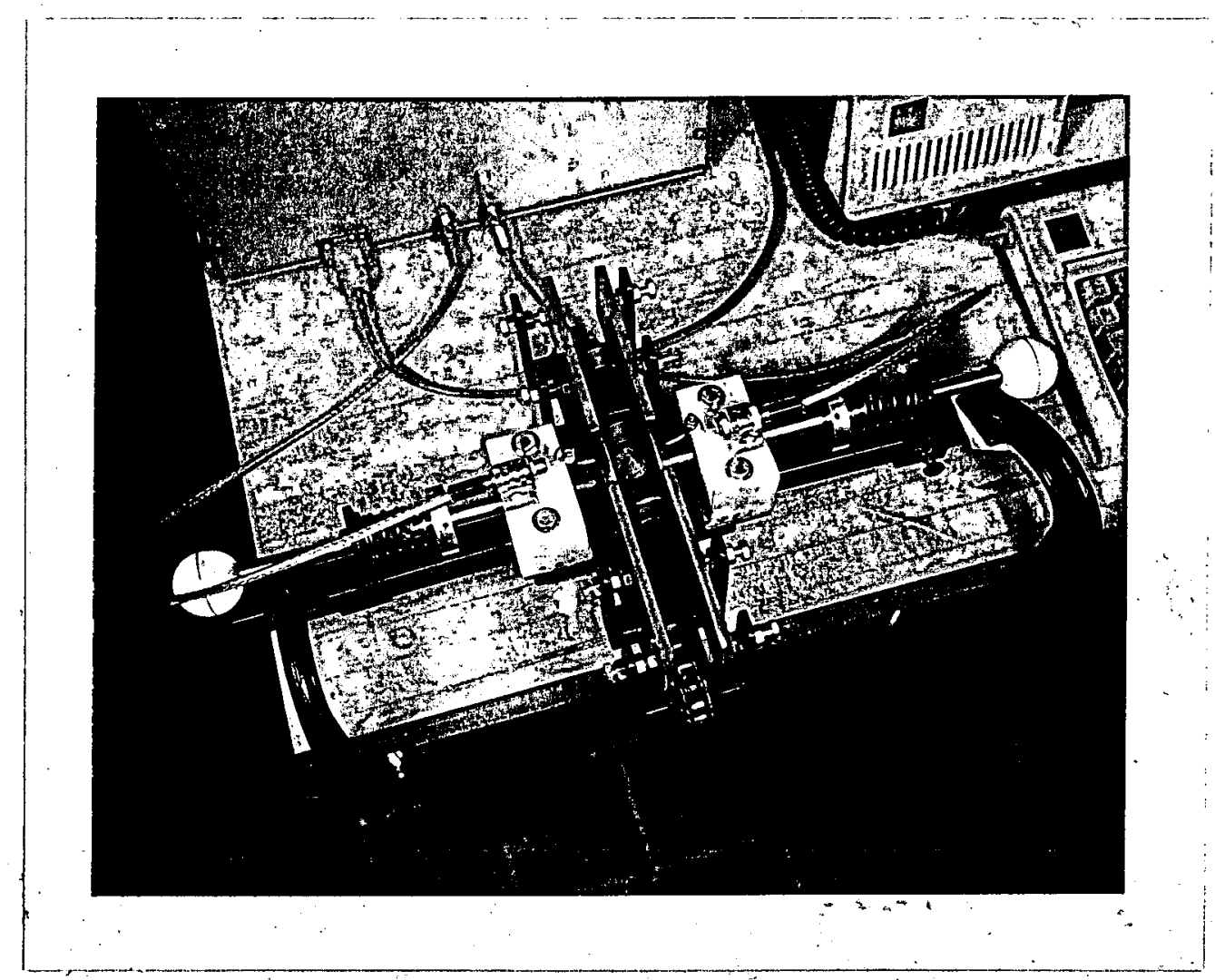

Figure 4. Duplicate electrode assembly and conveyor section designed, developed, and built in Israel and shipped to the U.S.A. for use of the American team in testing and calibrating the electronic pecan moisture sensing system. 


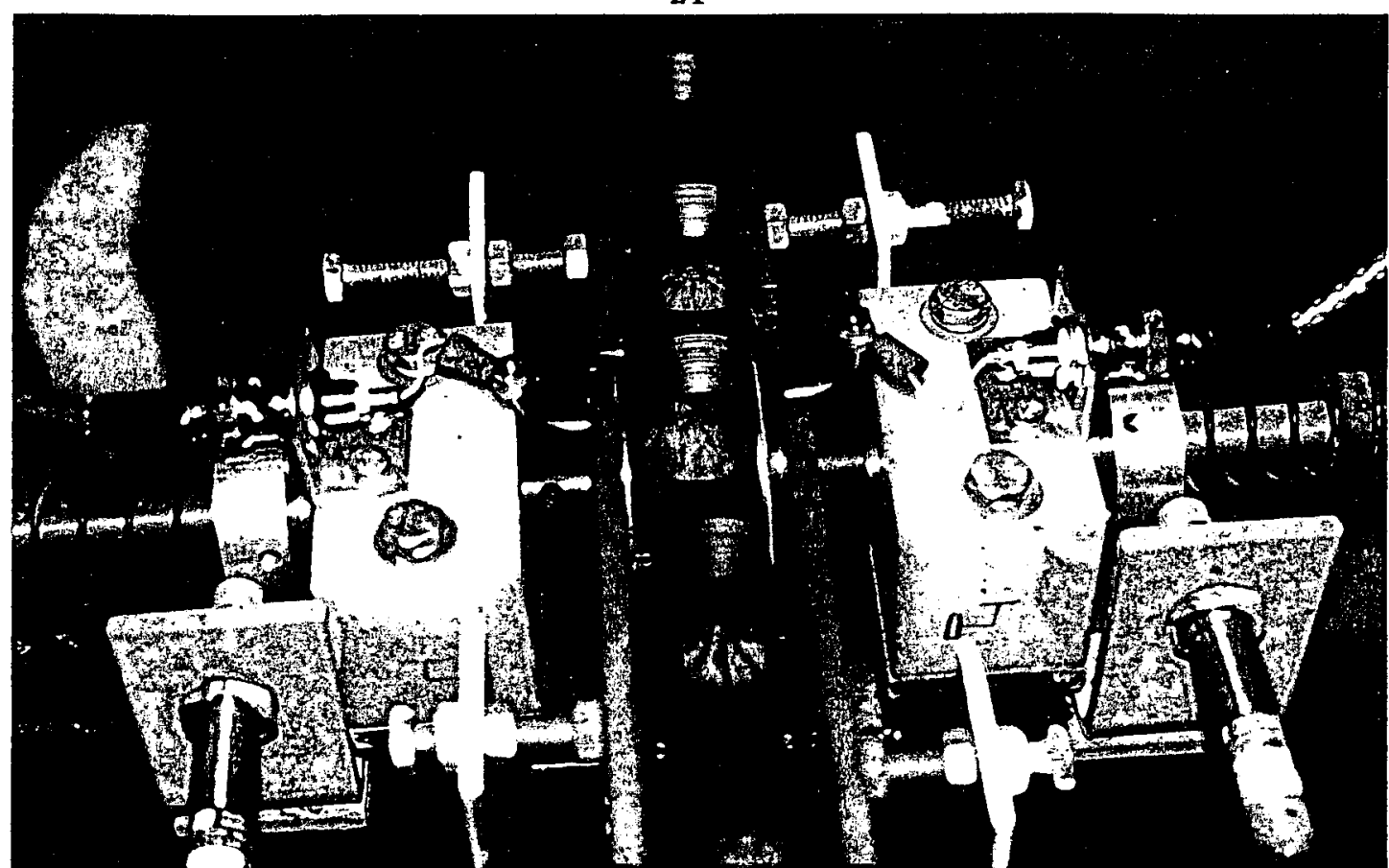

Figure 5. The parallel-plate electrode assembly and Delrin pecan-cell conveyor in the on-line system designed, developed, and built in Israel.

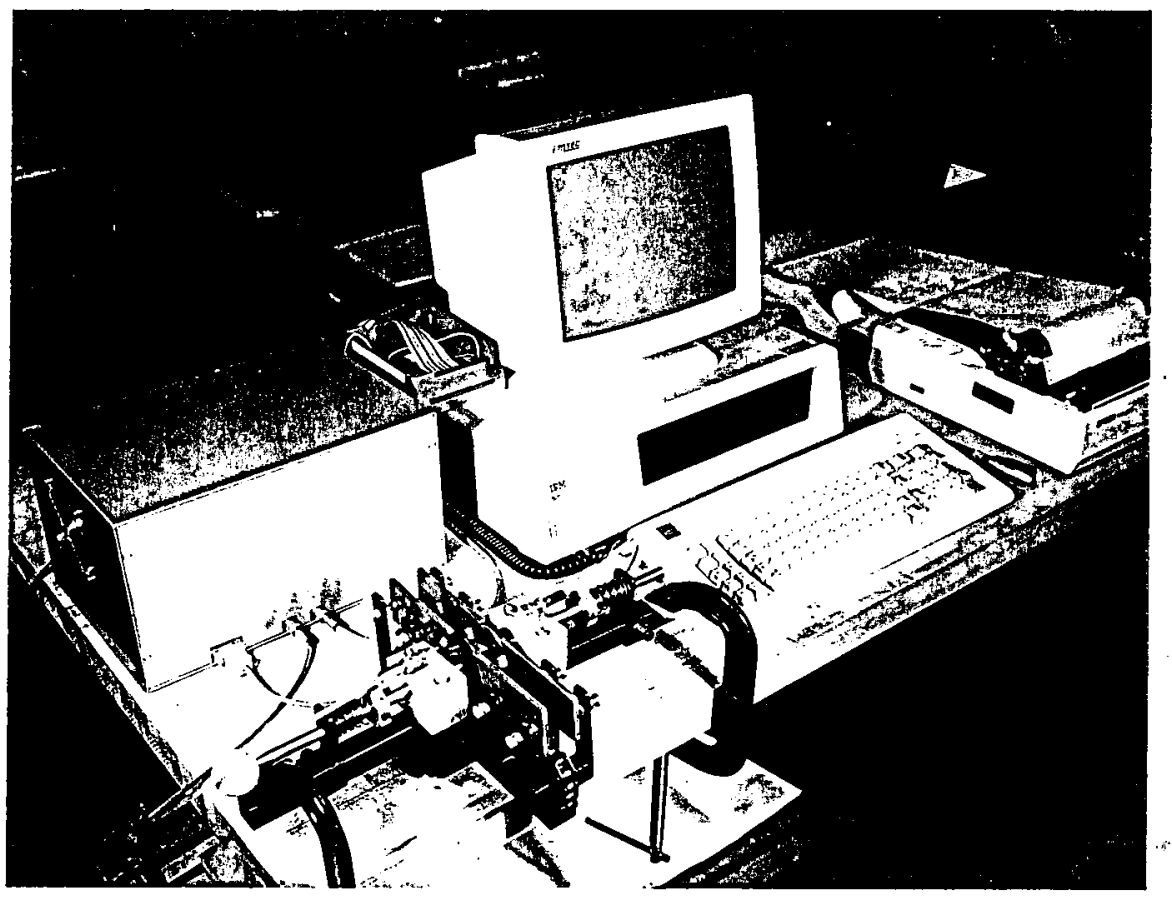

Figure 6. The electronic dual-frequency RF impedance measuring unit, designed, developed and built in the United States, (left) connected to the parallel-plate electrode sensor assembly (designed, developed, and built in Israel) and the personal computer for testing and calibration work. 


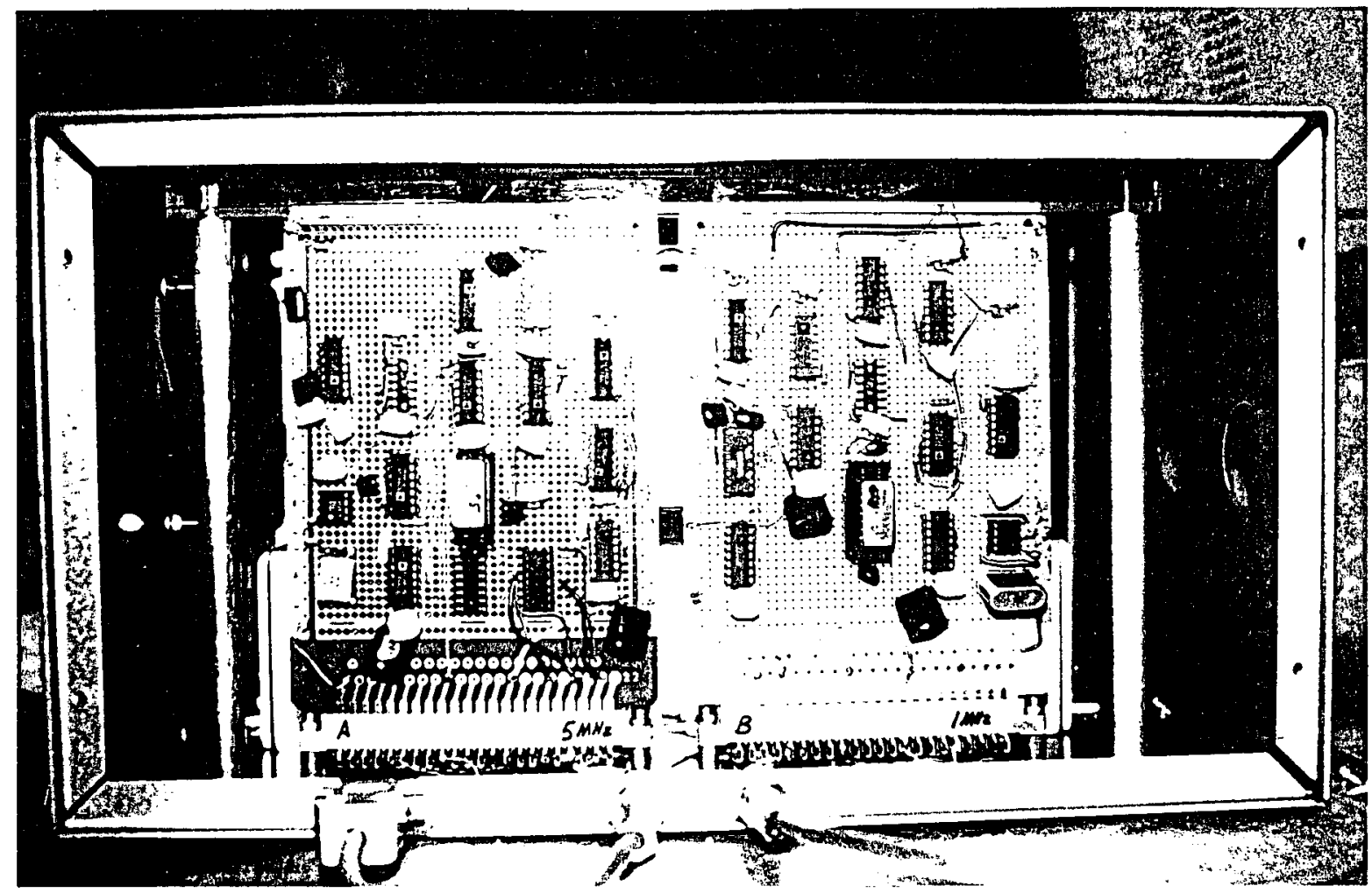

Figure 7. Electronic unit with rear panel removed, showing the 5-MHz and 1-MHz printed circuit boards readily accessible for testing and adjustment.

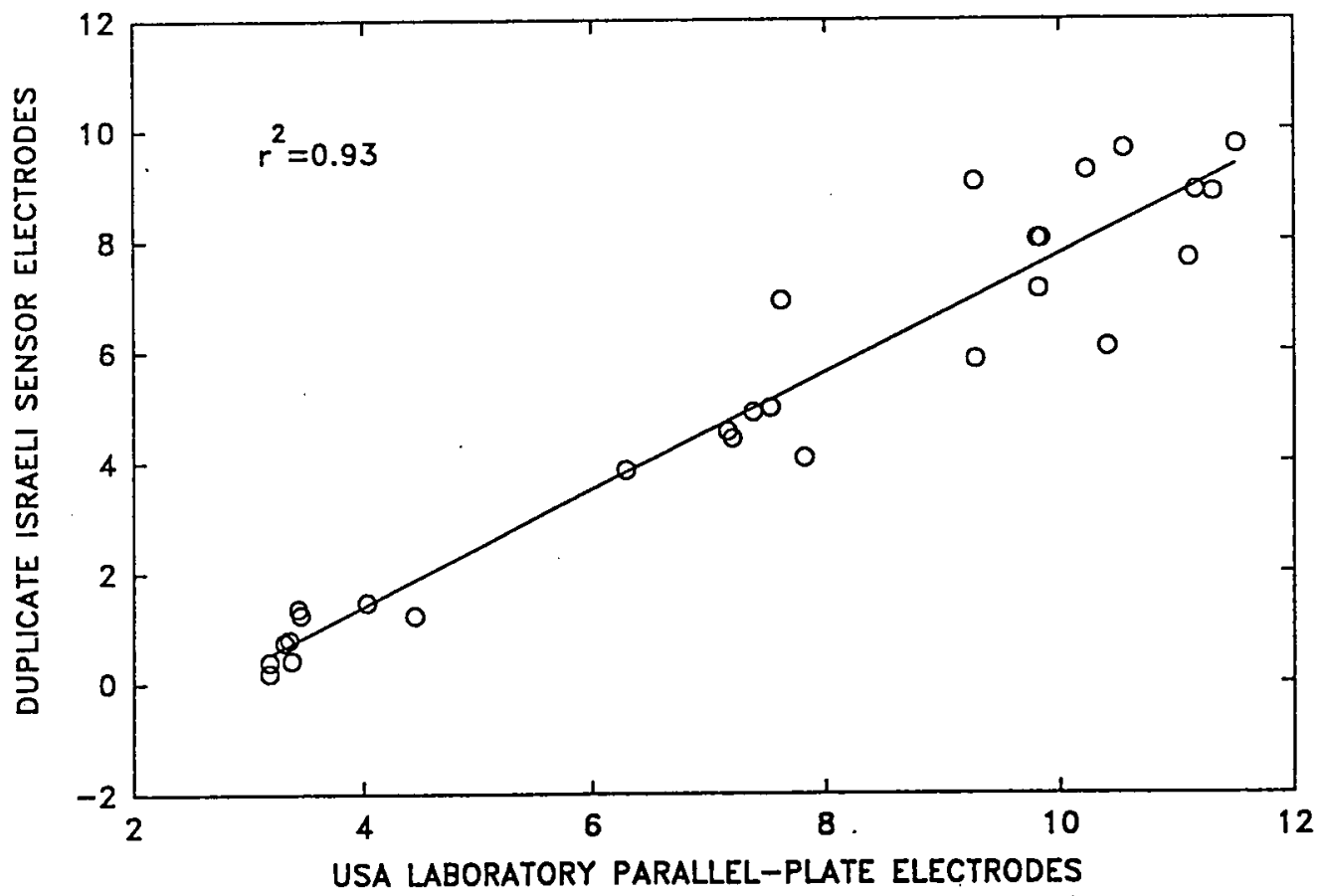

Figure 8. Comparison of pecan moisture contents determined by dual-frequency impedance measurements with the Hp 4192A Impedance Analyzer on the duplicate Israeli sensor electrodes and similar measurements on the parallel-plate electrode assembly used for the laboratory studies. 


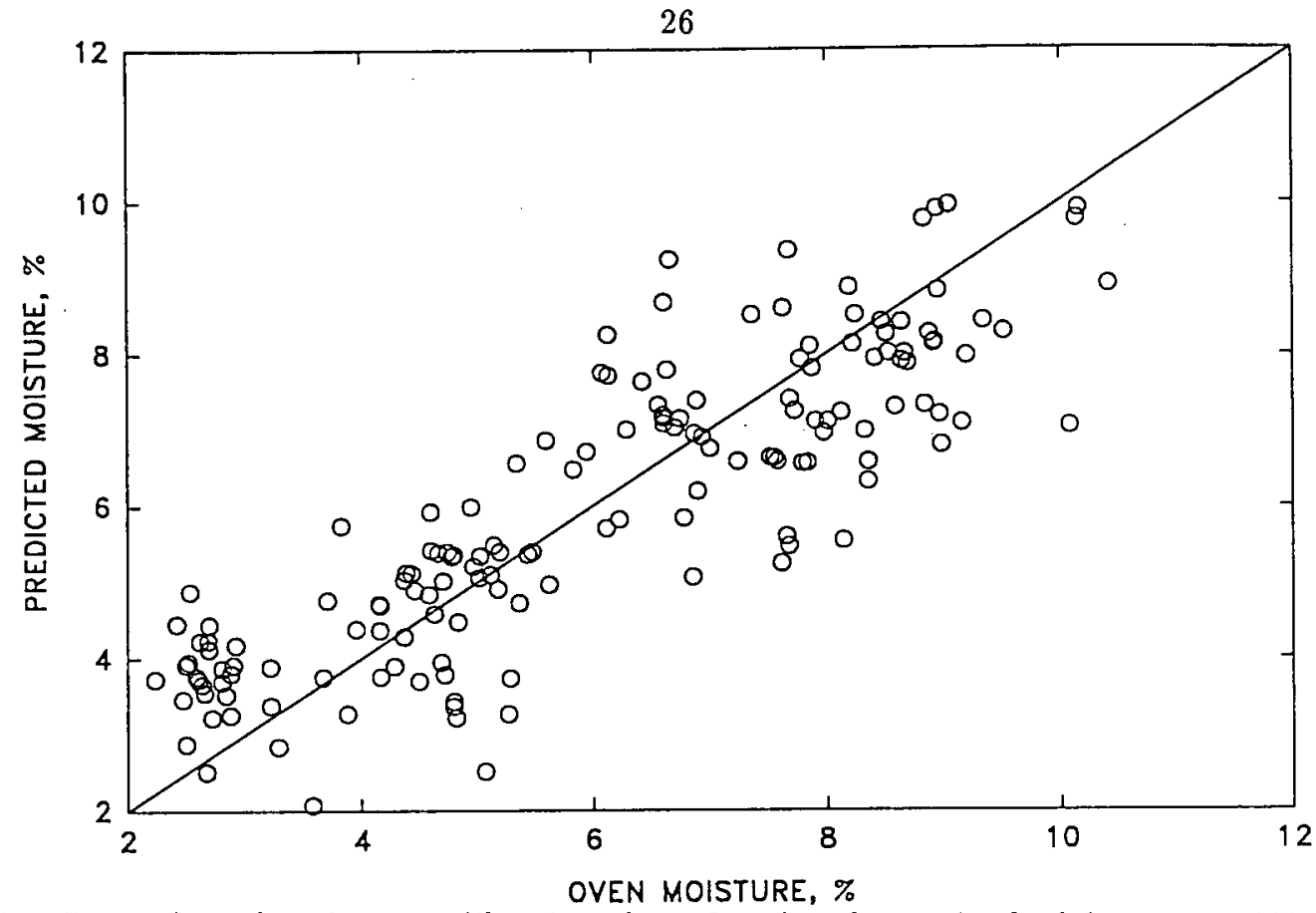

Figure 9. Pecan kernel-moisture calibration data for the electronic dual-frequency RF impedance measuring unit with the duplicate parallel-plate electrode sensor assembly when the electronic unit was shipped to Israel.

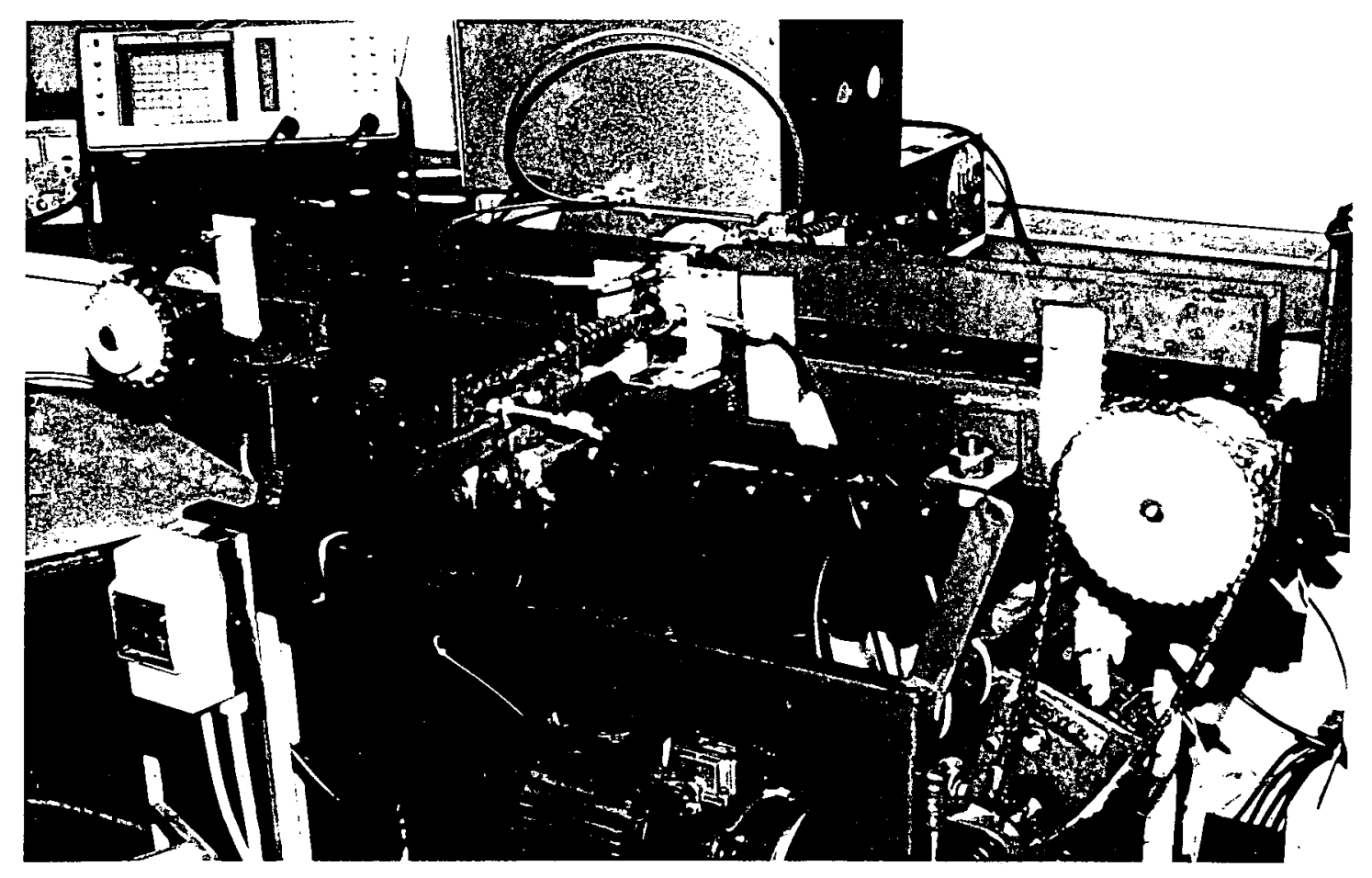

Figure 10. The individual pecan on-line moisture measurement system, including the stepwise conveyor, parallel-plate electrode sensor, and the electronic dual-frequency RF impedance measuring unit at the ARO Volcani Center, Bet Dagan, Israel. 


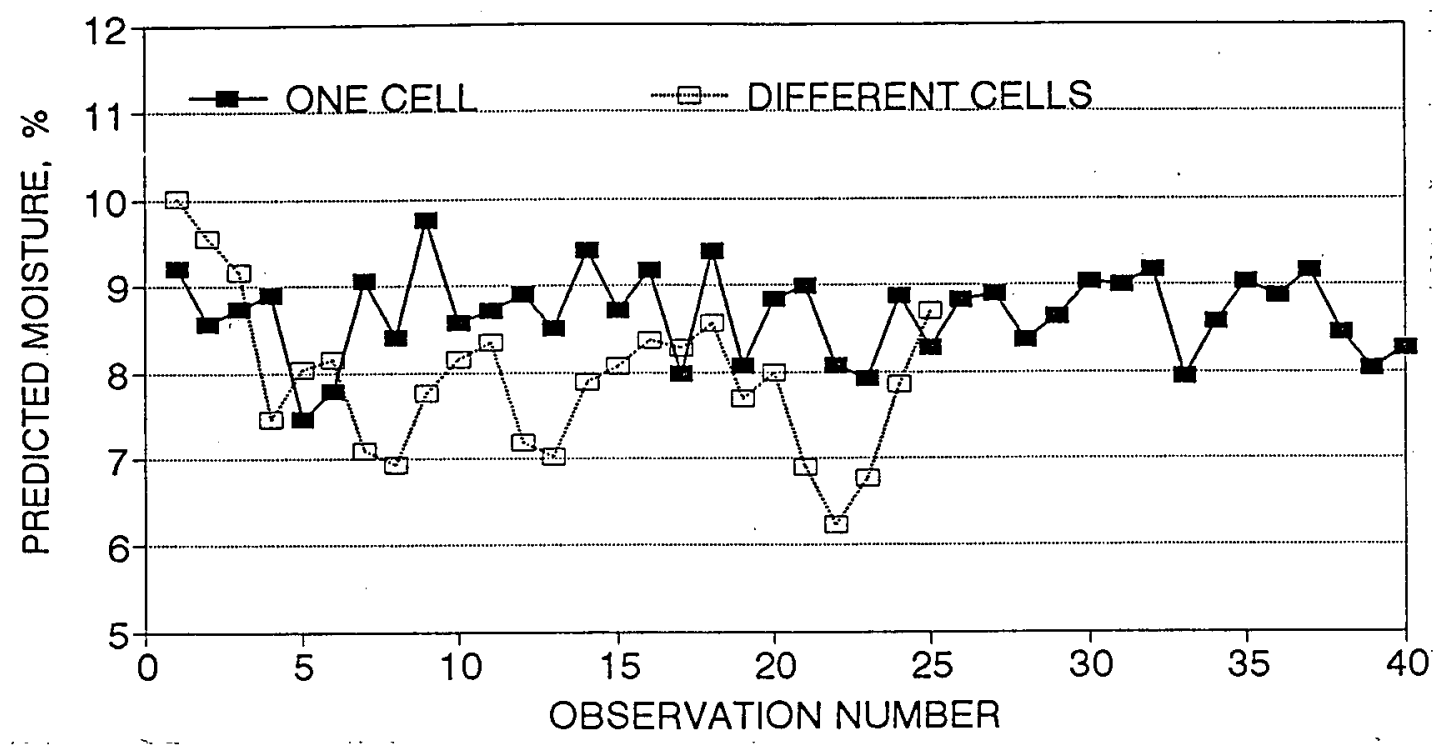

Figure 11. Repeatability of moisture determination on 2-in. by 1-in. diameter wooden cylinder in the Delrin pecan cells (moisture content computed on basis of pecan calibration).

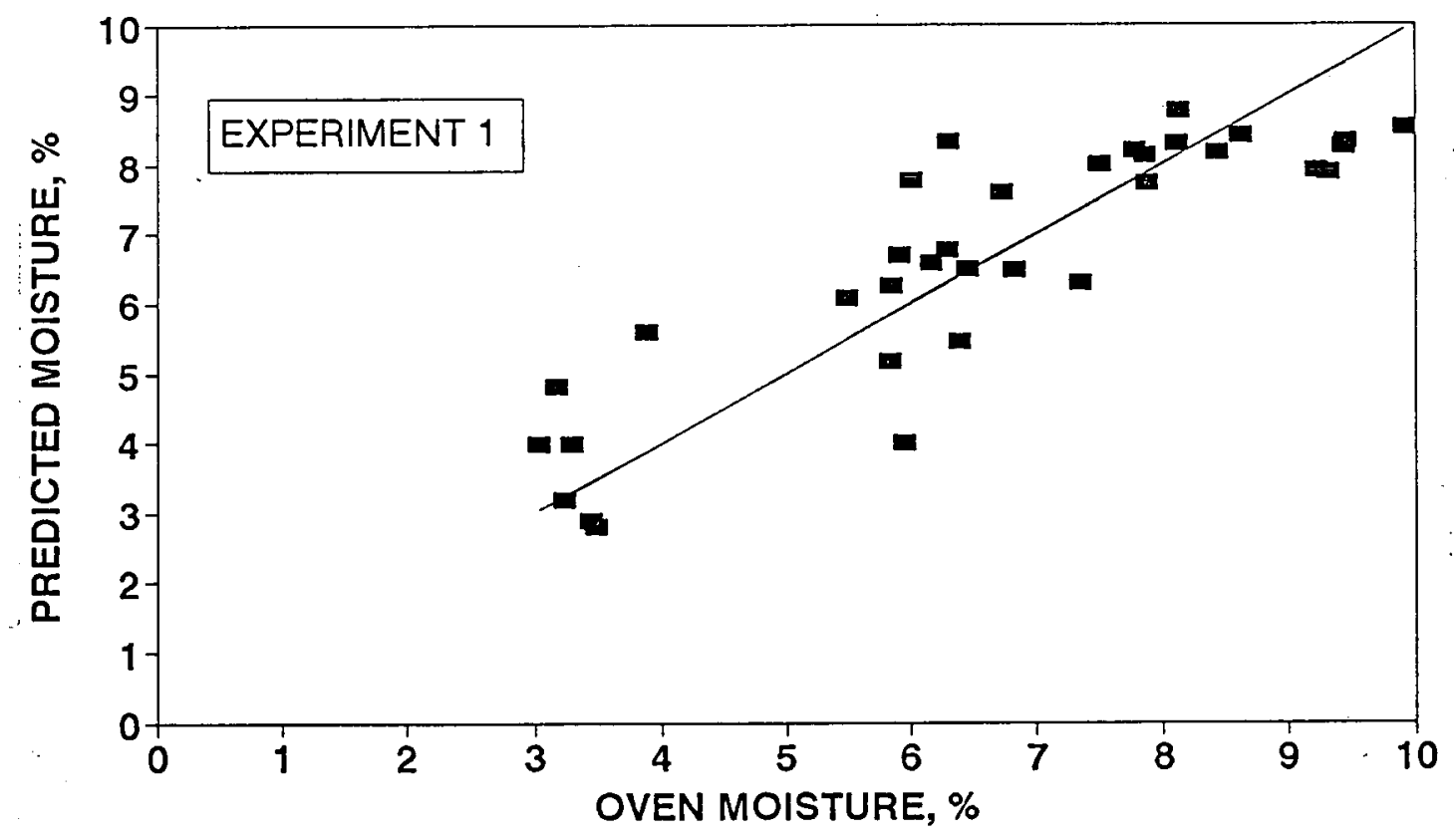

Figure 12. Calibration results for the RF impedance sensing of pecan kernel moisture content based on the vacuum-oven moisture reference-(Experiment 1). 


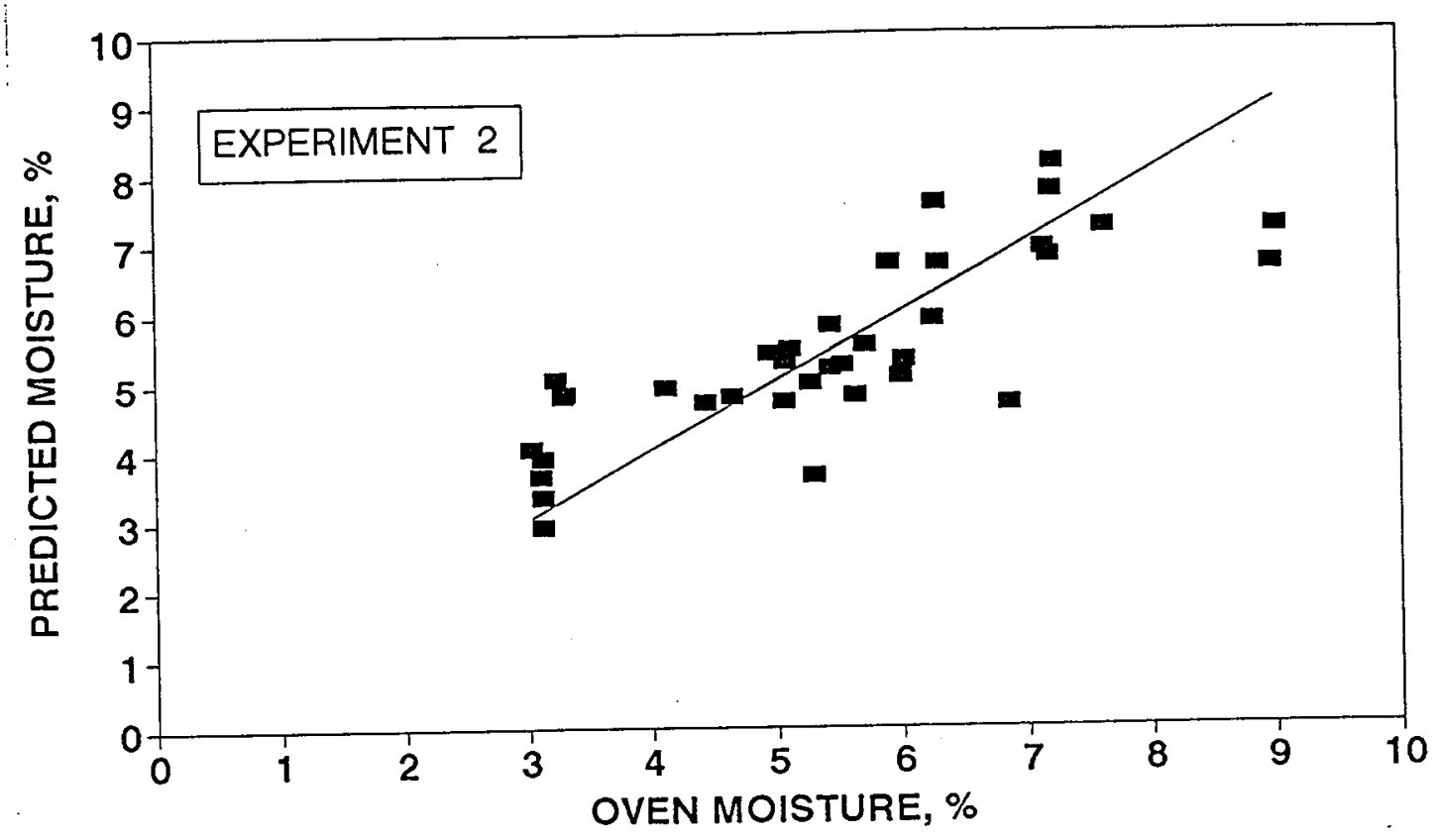

Figure 13. Calibration results for the RF impedance sensing of pecan kernel moisture content based on the vacuum-oven moisture reference (Experiment 2). 